\title{
Protection of meconium-induced lung epithelial injury by protease inhibitors
}

\begin{abstract}
Earlier work form this laboratory showed that exposure of alveolar epithelial cells (AECs) to meconium caused significant cell detachment and that meconium-induced detachment of cells was prevented by a protease inhibitor cocktail. Therefore, it was hypothesized that protease inhibitors might protect AEC monolayers against meconium-induced collapse of epithelial barrier function both in vitro and in vivo. To investigate this theory in vitro, albumin flux was measured across cultured, confluent monolayers of human type II derived cell line A549 on microporous filter inserts. Human meconium was collected from seven healthy full-term neonates and the samples were pooled and diluted prior to analysis. Exposure of AECs to $5 \%$ human meconium increased albumin flux across the cultured AEC monolayers, but the increase was significantly blocked by protease inhibitors $(\mathrm{P}<0.001)$. In C57/BL6 mice, intratracheal instillation of 5\% human meconium increased the passage of Evans Blue Dye (EBD) from the vascular compartment into the alveolar spaces, measured in bronchoalveolar lavage (BAL) fluid after intravenous injection of EBD. Moreover, intratrachial coinstillation of protease inhibitors prevented the meconium-induced increase in EBD passage into BAL fluid $(\mathrm{P}<0.01)$. The data presented herein clearly demonstrate that protease inhibitors protect $\mathrm{AEC}$ barrier function against meconium-induced injury, and suggest the future possibility of using protease inhibitors in the treatment of meconium aspiration syndrome.
\end{abstract}

Keywords: local angiotensin system, apoptosis, alveolar type ii cells, neonatal lung injury
Volume 4 Issue 5 - 2017

\author{
Ota C,' Gopallawa I,' Ivanov V, ${ }^{2}$ Gewolb IH, ${ }^{2}$ \\ Uhal BD' \\ 'Department of Physiology, Michigan State University, USA \\ ${ }^{2}$ College of Human Medicine, Department of Pediatrics, Michigan \\ State University, USA
}

Correspondence: Bruce D Uhal, Department of Physiology, Michigan State University, 3197 Biomedical and Physical Sciences Building, East Lansing, MI 48824, Michigan, USA, Tel (5 I7)884-5। 3 I, Fax (5।7)355-5 I25, Email uhal@msu.edu

Received: October 22, 2017 | Published: November 20, 2017

\section{Introduction}

Meconium aspiration syndrome (MAS) is a neonatal respiratory dysfunction that results in severe lung failure, associated with high morbidity and mortality among otherwise healthy newborns. ${ }^{1}$ Aspiration of meconium which is suggested to be initiated by fetal distress or intrauterine aspiration, has shown to promote inflammation, airway obstruction, disrupted lung development and neutralize the pulmonary surfactant in newborns. ${ }^{2,3}$ The exact mechanisms of MAS, largely remain unclear and treatments are still limited to mechanical ventilation, surfactant therapy and airway cleaning. Therefore, it is important to discover the potential treatments based on improved understanding of the pathophysiology of MAS. Alveolar epithelial cells (AECs) are the lining of the alveoli and are composed of type I and type II AECs that are mainly responsible for gaseous exchange and barrier functions. Type II AECs are particularly important due to synthesize of the pulmonary surfactant, repair after lung injury, maintain the alveolar-capillary barrier, secrete antimicrobial agents, release factors that inhibit fibroblast proliferation and play a key role in alveolar transepithelial water movement. ${ }^{4,5}$ Therefore, damage to AECs changes alveolar permeability and fluid transport through the AEC barrier and causes pulmonary edema. Several studies have suggested that meconium aspiration injures airway and alveolar lining cells to induce alveolar epithelial cell death by apoptosis and may change vascular or epithelial permeability. ${ }^{6}$ However, the exact mechanism(s) of meconium-induced epithelial barrier dysfunction is unclear and need to be further investigated in order to understand the pathogenesis of MAS.

Previous work by Antonowicz and Shwachman, demonstrated that human meconium contains pancreatic and intestinal digestive enzymes. ${ }^{7}$ In the later years, studies conducted by El Maradny et al. ${ }^{8}$ showed that the concentration of urinary trypsin inhibitor-related substance in the amniotic fluid was significantly higher in the neonatal urine than in adult urine. ${ }^{8}$ Thereafter, it was demonstrated that urinary trypsin inhibitor prevented the meconium-induced intestinal damage via inhibiting IL-8 when meconium and urine were mixed together. Thus, it was theorized that protease inhibitors may control the harmful effect of the enzymes in meconium. Based on the idea of proteases in meconium, previous work in this laboratory revealed that the human AEC-derived cell line A549 cells were detached from culture dishes when incubated with meconium and more importantly, that protease inhibitors prevented the cell detachment. ${ }^{10}$ This led to the hypothesis that protease inhibitors might preserve the integrity of alveolar epithelial monolayers from meconium-induced injury and improve epithelial barrier function. To investigate this hypothesis, an experimental microporous filter system was used to measure the flux of albumin across functionally intact alveolar epithelial cell monolayers in vitro. Likewise, to validate these results, an in vivo study in mice was performed to determine whether protease inhibitors might preserve mouse lungs from barrier collapse induced by meconiumaspiration. We report here the ability of protease inhibitors to prevent both meconium-induced transepithelial albumin flux in vitro and meconium-induced epithelial barrier collapse in mouse lungs in vivo.

\section{Materials and methods}

\section{Reagents and materials}

Protease inhibitor cocktail (EDTA-free) and DNase free RNase were obtained from Roche Applied Sciences (Nutley, NJ). BODIPYalbumin was purchased from Molecular Probes (Eugene, OR). Evans blue dye (EBD) was purchased from Sigma Aldrich (St. Louis, MO). Transwell ${ }^{\circledR}$ nucleopore filters (diameter $6.5 \mathrm{~mm}$, pore size $0.4 \mu \mathrm{m}$, growth area $0.33 \mathrm{~cm}^{2}$ ) were obtained from Corning (Lowell, MA). All the other materials were of reagent grade and were purchased from Sigma Aldrich. 


\section{Meconium collection, storage and preparation}

First pass human meconium was collected from seven healthy fullterm neonates at Sparrow Hospital Lansing, Michigan under protocols approved by the Institutional Review Board. Collected meconium samples were stored at $4{ }^{\circ} \mathrm{C}$ for no more than $24 \mathrm{~h}$ and were transported on ice to the laboratory. Next, the samples were pooled, thoroughly mixed and were divided into small aliquots. The samples were stored at $-80^{\circ} \mathrm{C}$ and were thawed directly before use. On the day of the in vitro experiment samples were diluted to a final concentration of $5 \%$ (wt/vol) in serum-free F12 medium or in saline (in vivo study). The purified supernatant was obtained by centrifugation at $5000 \mathrm{rpm}$ for $20 \mathrm{~min}$ at $4^{\circ} \mathrm{C}$, following sterilization via $0.2 \mu \mathrm{m}$ filter as previously described by Zagariya et al. ${ }^{3}$

\section{Animal handling and surgical procedures}

All surgical procedures and methods of anesthesia were approved by the university committee on animal use and care of Michigan State University, East Lansing, MI. Adult female C57/BL6 mice (6-7 weeks of age, 17-20 g of weight) were housed in a satellite facility at Michigan State University laboratory animal resources. Anesthesia for meconium instillations and for terminal surgery was performed by a single intraperitoneal injection of pentobarbital at a concentration of $60 \mathrm{mg}$. kg-1. A small midline incision was made on the ventral aspect of the neck to expose the trachea, and an endotracheal cannula was placed through the mouth. Sterilized meconium (5\%) with or without protease inhibitor cocktail $\left(2.5 \mathrm{mg} . \mathrm{kg}^{-1}\right)$ was instilled through endotracheal injection followed by $0.3 \mathrm{ml}$ air to ensure liquid dispersion into distal airways. The control animals were instilled with equivalent volumes of saline. The skin incision was closed with 4-0 nylon suture and the mice were allowed to breathe spontaneously in the room air.

\section{Cell culture and preparation of filters}

The human lung adenocarcinoma cell line A549 was obtained from the American Type Cell Culture Collection and cultured in Ham's F12 medium supplemented with 10\% fetal bovine serum (FBS). All cells were grown in $100 \mathrm{~mm}$ culture dishes or 24 well chambers and all experiments were conducted in serum-free Ham's F12 medium at sub-confluent cell densities. Transwell@ nucleopore filters were sterilized overnight with UV light and A549 cells were plated on the luminal side of the filters to obtain an intact monolayer in the presence of complete medium in the outer chamber. After $96 \mathrm{~h}$, both inner and outer chambers were washed, replaced with serum-free F12 medium and were divided into three experimental groups. Next each of the groups was treated with $5 \%$ meconium solution in the absence or presence of protease inhibitor cocktail. The control groups were immersed in serum-free F12 medium. In all studies cells were exposed to protease inhibitors for $30 \mathrm{~min}$ before overnight exposure to $5 \%$ meconium.

\section{Determination of AEC barrier function: in vitro and in vivo}

\section{Albumin flux}

After treating the cells with the above mentioned conditions, BODIPY-albumin $(1 \mu \mathrm{g} / \mu \mathrm{l})$ was added into the outer chambers and unlabeled albumin into the inner chambers. Thereafter, $50 \mu 1$ aliquots were taken (at time $=0$ ) from inner chambers into 96 well-chambers each hour. The liquid removed from inner chambers was replaced with $50 \mu \mathrm{l}$ of unlabeled albumin. The heights of liquids in both the inner and outer chambers were adjusted to be the same without any hydrostatic differences. Each BODIPY-Albumin measurement was the average of eight repeated experiments. BODIPY fluorescence in the hourly samplings from inner chambers was determined on FL600 fluorescence microplate reader (BioTek Inc., Winooski, VT).

\section{Evans blue dye (EBD) staining}

After $24 \mathrm{~h}$ of exposure to meconium, all animals were injected with $50 \mathrm{mg}$. $\mathrm{kg}^{-1}$ of EBD via inferior vena cava, dissolved in sterile saline $(5 \mathrm{mg} / \mathrm{ml})$. Ten minutes after the instillation of EBD, bronchoalveolar lavage (BAL) was collected. An endotracheal cannula was installed surgically and three lavages of $0.3 \mathrm{ml}$ each in sterile saline were slowly instilled and collected by gravity. Animals were killed by exsanguination immediately after collecting BAL fluid. Next, the BAL fluid, supplemented with protease inhibitors, was centrifuged at $3000 \mathrm{rpm}$ for $10 \mathrm{~min}$ to remove the cells and the supernatant was stored at $-20^{\circ} \mathrm{C}$ until use. Absorbance was measured in the BAL fluid using the FL600 fluorescence microplate reader at $620 \mathrm{~nm}$ wavelength.

\section{Light microscopy}

The morphologic and functional status of the monolayers on the filters was assessed by fluorescence microscopy as previously described by Filippatos et al. ${ }^{11}$ The adherent monolayers were fixed with $70 \%$ ethanol at $4^{\circ} \mathrm{C}$ for $30 \mathrm{~min}$. Next, the ethanol was aspirated and replaced with $300 \mu \mathrm{l}$ of propidium iodide solution $(5 \mu \mathrm{g} / \mathrm{ml})$ dissolved in phosphate-buffered saline in the presence of DNase-free RNase. Photo-microscopy was performed with a Zeis Jena inverted epifluorescence microscope. Red fluorescence $(>590 \mathrm{~nm})$ was observed through a 0590 barrier filter following excitation at $485 \mathrm{~nm}$.

\section{Results}

To investigate the AEC barrier disruption in response to meconium, A549 cells were plated at a cell density of $1.8 \times 10^{5} \mathrm{cells} / \mathrm{cm}^{2}$ on the filters. As Figure 1 shows, the cells that received meconium indicates a significant increase in the flux of BODIPY-albumin through the AEC monolayers into inner chambers compared to the control cells that did not receive meconium. Moreover, albumin flux through the AEC monolayers of meconium plus protease inhibitor treated group was considerably decreased compared to the cells treated with meconium alone. Next, the cells were subjected to propidium iodide (PI) assay to facilitate assessment of AEC monolayer after in vitro assays of albumin flux. As Figure 2 depicts, uniformly distributed AEC monolayer was seen in the control group but in contrast AEC layer was disrupted and the cells were detached in the meconium treated group. However, the cells that received meconium in the presence of protease inhibitors, maintained evenly distributed AECs. To determine the barrier function of AEC monolayers in vivo, mice were challenged with intratracheal instillation of human meconium, supplemented with protease inhibitors or vehicle as described in the materials and methods section. Figure 3 shows that meconiuminstilled mice exhibited EBD absorbance that were significantly larger compared to BAL fluid in control animals. More importantly, protease inhibitors (instilled with the meconium) prevented the meconiuminduced increase in EBD in the mouse lung BAL fluid.

\section{Discussion}

Meconium aspiration syndrome (MAS) is a life-threatening disorder in newborns and the pathogenic conditions of MAS still remain 
incompletely understood. MAS is a major clinical problem associated with newborns and has shown to promote airway obstruction, inflammation, surfactant inactivation, cell apoptosis and lung injury leading to respiratory failure. ${ }^{12}$ In this report, we show that meconiuminduced lung epithelial injury is diminished by co-treatment with a protease inhibitor cocktail. To test the integrity of the epithelium in vitro, transfer of fluorescent (BODIPY)-albumin was measured across cultured AEC monolayers. As shown in Figure 1, BODIPY-albumin levels were significantly increased in cells that were treated with meconium compared to the control and the meconium plus protease inhibitor groups. Morphological analyses with propidium iodide (PI) showed (Figure 2) detachment of AEC monolayers from the filters after treatment with 5\% meconium. In contrast, the AEC monolayers incubated with $5 \%$ meconium plus protease inhibitor cocktail retained barrier integrity. These findings suggested that exposure to human meconium could promote detachment of alveolar lining cells at least in vitro and might therefore lead to epithelial barrier collapse and subsequent lung injury. The results reported herein are consistent with previous findings from this laboratory demonstrating the protective effects of protease inhibitors against meconium-induced disruptions of intracellular connections and AEC detachment. ${ }^{10}$

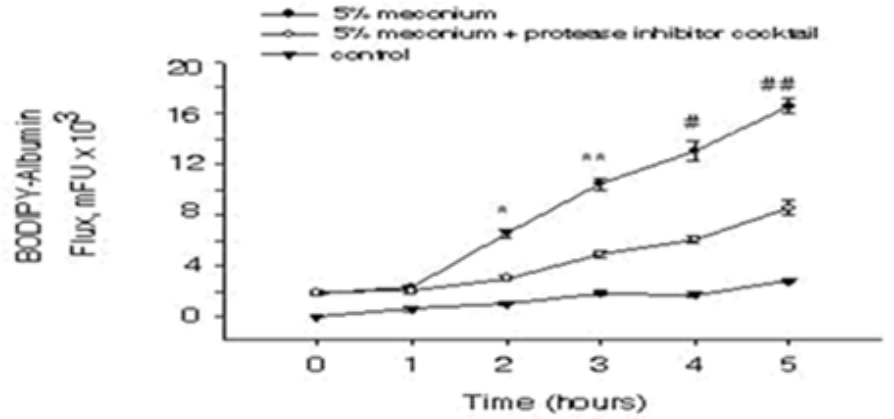

Figure I Induction of BODIPY-albumin flux in response to meconium in alveolar epithelial cells. After A549 cells were cultured on the luminal side of the filters as described in "Materials and Methods", the cells were treated with $5 \%$ human meconium in the presence or absence of protease inhibitors. Next BODIPY-albumin $(\mathrm{Img} / \mathrm{ml})$ was added into outer chambers and $50 \mu \mathrm{l}$ of aliquots were taken from inner chambers starting at time 0 . The BODIPY fluorescence was measured and was normalized. Bars are means $+S E n=8$; $* \mathrm{P}<0.001$, $* * \mathrm{P}<0.001, \# \mathrm{P}<0.001$, \#P $<0.001$ compared with $5 \%$ meconium + protease inhibitor cocktail group.

On the basis of these results and to further strengthen the in vitro data, it was hypothesized that a murine model of MAS might also reveal meconium-induced epithelial barrier collapse and further, a protease inhibitor cocktail might improve the condition pharmacologically. Dreyfuss et al. ${ }^{13}$ used an overinflated rat lung model to describe increased pulmonary microvascular permeability to albumin as a measure of alveolar/airway epithelial permeability. These authors injected radiolabeled albumin into the systemic circulation and thereafter measured recovery of the albumin in bronchoalveolar larvage (BAL) fluid. ${ }^{13}$ However, due to unexpected quenching of the BODIPY by lavage components, using the dye was precluded from the current experimental study. As an alternative, Evans Blue Dye (EBD) was preferred since it has been used as a sensitive marker for protein leakage from the vasculature into a variety of tissues. ${ }^{14}$ As shown in Figure 3, the BAL fluid from meconium-instilled mice displayed considerably larger EBD absorbance compared to the control mice after $24 \mathrm{~h}$ of instillation. However the induction of EBD absorbance was not observed after $6 \mathrm{~h}$ meconium instillation (data not shown). These data suggested that meconium caused the dye extravasation from the vascular to alveolar compartments in sub-acute stage following meconium aspiration in mice. In agreement with the study presented herein, Khan and others have described that aspiration of meconium in a similar murine model produced a significant induction of lymphocytes in BAL fluid on day $2 .{ }^{15}$ Although, several studies showed that meconium-induced lung injury occurred within 5 to 8 hours after instillation in a rat, rabbitor piglet model, it is a possibility that the responses to human meconium differ among species. ${ }^{16-18}$
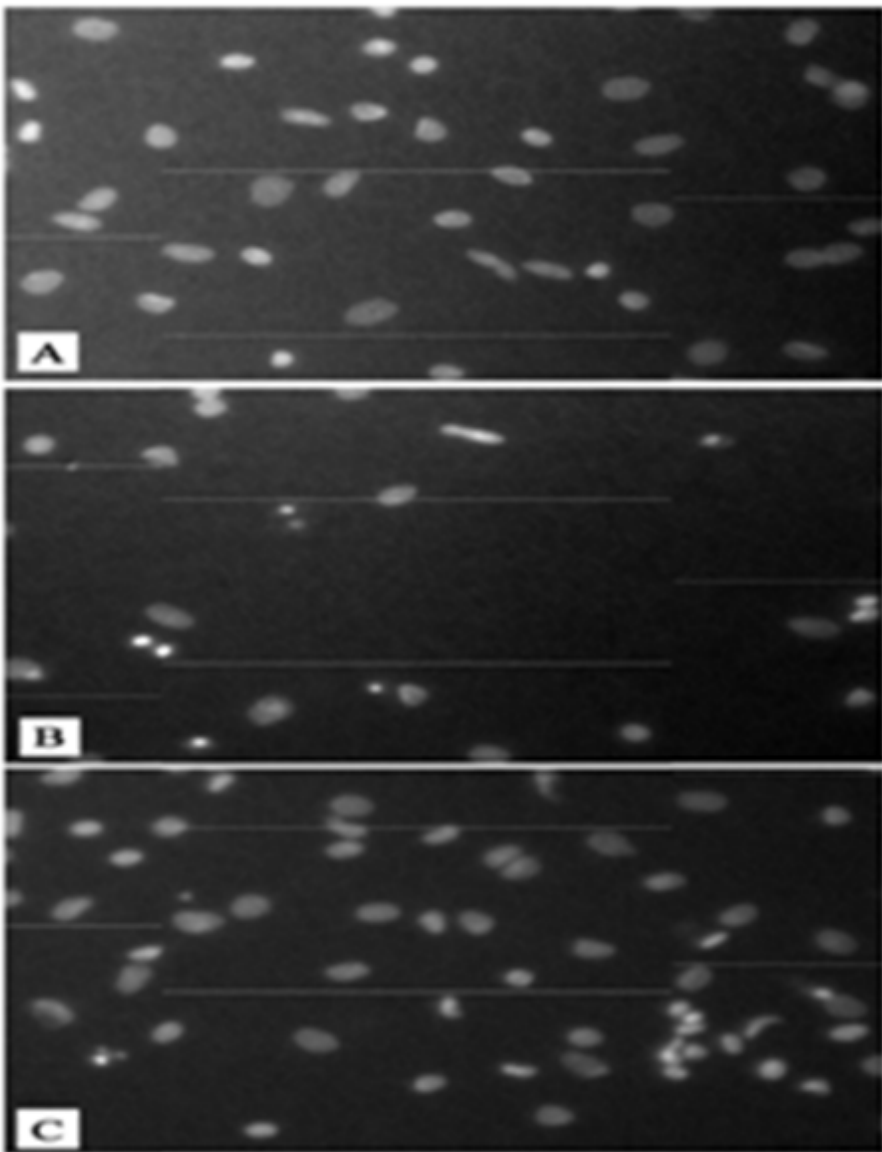

Figure 2 Fluorescence micrographs of alveolar epithelial cell distribution across filters. The adherent monolayers were fixed with $70 \%$ ethanol and were subjected to propidium iodide assay. Panel A shows the uniform distribution of control cells. Panel B shows the cells in the filters that received $5 \%$ meconium and cell detachment compared to the control cells. Panel $C$ shows the distribution of cells that received meconium in the presence of protease inhibitors.

Moreover, it was also shown that in experimental animal models aspiration of both heterologous and homologous meconium alters the pulmonary vascular permeability and is unclear whether the changes are due to a direct effect of meconium on the epithelium or due to the activation of local factors. ${ }^{19}$ Human meconium has shown to consist of numerous substances and therefore the effects of these components on the newborn lung development need to be further extrapolated..$^{20}$ Additionally, several authors have suggested that effects of meconium are not restricted to the lungs, but may also cause deleterious actions on distant organs through systemic dispersion and need to be further investigated. 


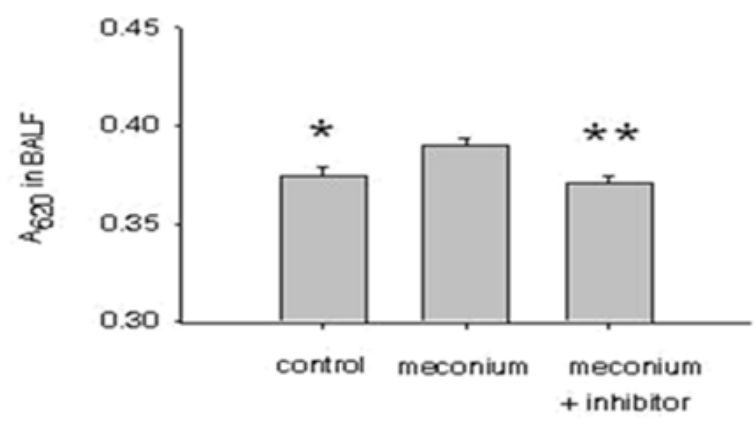

Figure 3 Meconium-induced EBD absorbance in the mouse lung. Mice were instilled with $5 \%$ meconium in the presence or absence of protease inhibitors ( $\left.2.5 \mathrm{mg} . \mathrm{kg}^{-1}\right)$ for $24 \mathrm{~h}$. Next, mice were injected with $50 \mathrm{mg} . \mathrm{kg}^{-1}$ of Evans Blue Dye (EBD) dissolved in saline. After $10 \mathrm{~min}$, bronchoalveolar lavage (BAL) fluid was collected and after centrifugation at 3000rpm the absorbance of $\mathrm{EBD}$ was measured. Bars are mean $+\mathrm{SE} ; * \mathrm{P}<0.0 \mathrm{I}$, $* * \mathrm{P}<0.0 \mathrm{I}$ compared to $5 \%$ meconium group.

Several experimental studies have attempted to control meconiuminduced lung injury pharmacologically, such as administration of corticosteroids to diminish the inflammatory response, restriction of the induction of apoptotic signaling network, serpins (inhibitors of proteases), nitrogen oxide and phospholipase A2 (PLA2) inhibitors. ${ }^{21-23}$ Although, studies have demonstrated beneficial effects of these treatments, there may be complications resulting from these drugs. Hence, more understanding of the pathogenicity and underlying mechanisms of the MAS are required since there is still a lack of safe and effective treatment. The study reported herein used a protease inhibitor cocktail which was shown to inhibit trypsin, chymotrypsin, papain, and pancreas-extract. It will be of interest to identify the specific inhibitors required to prevent lung injury caused by meconium and to determine whether or not the individual inhibitors themselves might have harmful effects on the respiratory system. Additionally, in these experiments protease inhibitors were co-administered together with $5 \%$ human meconium. In the clinical setting, however, protease inhibitors would likely to be administered after the aspiration of meconium and therefore could react differently than discussed in these experiments. Therefore, further study is needed to find the effective timing or dose for the appropriate inhibitors to be considered for MAS.

Several studies demonstrated the induction of AEC apoptosis in experimental MAS models and therefore was theorized that pharmacological inhibition of apoptotic factors may provide the potential for therapeutic manipulation of MAS. Additional experimental studies have shown the activation of a local angiotensin (ANG) system in response to meconium. ${ }^{24}$ Several lines of investigations have supported the theory that exposure to meconium induces angiotensinogen (AGT) mRNA in newborn rabbits. ${ }^{25}$ This suggests, the upregulation of AGT and its effector peptide angiotensin II in newborns in response to meconium, a similar mechanism that is also present in adult lung diseases. ${ }^{26}$ In a related study, of newborn rabbits Rosenfeld et al. ${ }^{27}$ showed exposure to meconium induces angiotensin receptor (AT1) expression and further losartan, an antagonist for the AT1 receptor attenuates meconium-induced AEC apoptosis in newborn rabbit lung. ${ }^{27}$ It was also demonstrated that pretreatment with captopril, an ACE inhibitor, prevented meconiuminduced upregulation of interleukins and diminished AEC apoptosis. ${ }^{28}$
In summary, the study reported here, demonstrated that the barrier function of the intact alveolar epithelial monolayers is disrupted by human meconium and that a protease inhibitor cocktail significantly attenuated the meconium-induced loss of barrier function. In addition, the study also supported that in a mouse model of meconium aspiration syndrome, a protease inhibitor cocktail prevented meconium-induced increase in markers of lung edema formation. Thus, this study demonstrated the future therapeutic potential of protease inhibitors for pharmacological manipulation of meconium-induced lung injury in newborns.

\section{Acknowledgments}

This work was supported by HL 45136 to B.D.U.

\section{Ethical statement}

This study was approved by the Institutional Review Board of Michigan State University, East Lansing, MI.

\section{Conflicts of interest}

The authors have no conflicts to declare.

\section{References}

1. Ivanov VA. Meconium aspiration syndrome treatment-New approaches using old drugs. Med Hypotheses. 2006;66(4):808-810.

2. Kääpä PO. Meconium aspiration syndrome (MAS)-Where do we go? Research perspectives. Early Hum Dev. 2009;85(10):627-629.

3. Zagariya A, Bhat R, Uhal B, et al. Cell death and lung cell histology in meconium aspirated newborn rabbit lung. Eur J Pediatr. 2000;159:819826.

4. Uhal BD. Epithelial apoptosis in the initiation of lung fibrosis. Eur Respir J Suppl. 2003;44:7s-9s.

5. Ward HE, Nicholas TE. Alveolar type I and type II cells. Aust NZ J Med. 1984;14(5 Suppl 3):731-734.

6. Zagariya A, Bhat R, Chari G, et al. Apoptosis of airway epithelial cells in response to meconium. Life Sci. 2005;76(16):1849-1858.

7. Antonowicz I, Shwachman H. Meconium in health and in disease. $A d v$ Pediatr. 1979;26:275-310.

8. el Maradny E, Kanayama N, Halim A, et al. Urinary trypsin inhibitor has a protective effect on the amnion. Gynecol Obstet Invest. 1984;38(3):169-172.

9. Olguner M, Hakgüder G, Ateş O, et al. Urinary trypsin inhibitor present in fetal urine prevents intraamniotic meconium-induced intestinal damage in gastroschisis. J Pediatr Surg. 2006;41:1407-1412.

10. Ivanov VA, Gewolb IH, Uhal BD. A new look at the pathogenesis of the meconium aspiration syndrome: a role for fetal pancreatic proteolytic enzymes in epithelial cell detachment. Pediatr Res. 2010;68(3):221224.

11. Filippatos GS, Hughes WF, Qiao R, et al. Mechanisms of liquid flux across pulmonary alveolar epithelial cell monolayers. In Vitro Cell Dev Biol Anim. 1997;33(3):195-200.

12. Vain NE, Szyld EG, Prudent LM, et al. What (not) to do at and after delivery? Prevention and management of meconium aspiration syndrome. Early Hum Dev. 2009;85(10):621-626.

13. Dreyfuss D, Soler P, Saumon G. Spontaneous resolution of pulmonary edema caused by short periods of cyclic overinflation. J Appl Physiol. 1992;72(6):2081-2089. 
14. Patterson CE, Rhoades RA, Garcia JG. Evans blue dye as a marker of albumin clearance in cultured endothelial monolayer and isolated lung. J Appl Physiol. 1992;72(3):865-873.

15. Khan AM, Elidemir O, Epstein CE, et al. Meconium aspiration produces airway hyperresponsiveness and eosinophilic inflammation in a murine model. Am J Physiol Lung Cell Mol Physiol. 2002;283(4):L785-L790.

16. Lukkarinen H, Laine J, Lehtonen J, et al. Angiotensin II receptor blockade inhibits pneumocyte apoptosis in experimental meconium aspiration. Pediatr Res. 2004;55(2):326-333.

17. Calkovska A, Mokra D, Drgova A, et al. Bronchoalveolar lavage with pulmonary surfactant/dextran mixture improves meconium clearance and lung functions in experimental meconium aspiration syndrome. Eur J Pediatr.12008;67:851-857.

18. Tølløfsrud PA, Medbø S, Solas AB, et al. Albumin mixed with meconium attenuates pulmonary dysfunction in a newborn piglet model with meconium aspiration. Pediatr Res. 2002;52(4):545-553.

19. Martínez-Burnes J, López A, Horney B, et al. Cytologic and biochemical changes associated with inoculation of amniotic fluid and meconium into lungs of neonatal rats. Am J Vet Res. 2001;62(10):1636-1641.

20. Lindenskov PHH, Castellheim A, Saugstad OD, et al. Meconium aspiration syndrome: possible pathophysiological mechanisms and future potential therapies. Neonatology. 2015;107(3):225-230.

21. Mokra D, Mokry J, Drgova A, et al. Intratracheally administered corticosteroids improve lung function in meconium-instilled rabbits. $J$ Physiol Pharmacol Off J Pol Physiol Soc. 2007;58(5):389-398.
22. Zagariya AM, Bhat R, Zhabotynsky E, et al. Characterization of serine/ cysteine protease inhibitor alpha1-antitripsin from meconium-instilled rabbit lungs. J Cell Biochem. 2005;96(1):137-144.

23. Schrama AJ, de Beaufort AJ, Sukul YR, et al. Phospholipase A2 is present in meconium and inhibits the activity of pulmonary surfactant: an in vitro study. Acta Paediatr. 2005;90(4):412-416.

24. Uhal BD, Abdul-Hafez A. Angiotensin II in apoptotic lung injury: potential role in meconium aspiration syndrome. $J$ Perinatol. 2008;28(3):S108-S112.

25. Zagariya A, Navale S, Uhal B, et al. Angiotensin Receptor Type I Blockade Inhibits Apoptosis in Meconium-Instilled Rabbit Lungs. $J$ Cancer Ther. 2011;2:629-637.

26. Vidyasagar D, Zagariya A. Studies of meconium-induced lung injury: inflammatory cytokine expression and apoptosis. J Perinatol. 2008;28(3):S102-S107.

27. Rosenfeld CR, Zagariya AM, Liu X, et al. Meconium Increases Type 1 Angiotensin II Receptor Expression and Alveolar Cell Death. Pediatr Res. 2008;63(3):251-256.

28. Zagariya A, Bhat R, Navale S, et al. Inhibition of meconium-induced cytokine expression and cell apoptosis by pretreatment with captopril. Pediatrics. 2006;117(5):1722-1727. 